\title{
Potential of essential oils for protection of grains contaminated by aflatoxin produced by Aspergillus flavus
}

\section{Renata H. Esper ${ }^{1}$, Edlayne Gonçalez ${ }^{1 *}$, Marcia O. M. Marques ${ }^{2}$, Roberto C. Felicio $^{3}$ and Joana D. Felicio ${ }^{1}$}

${ }^{1}$ Centro de Pesquisa e Desenvolvimento em Sanidade Animal, Instituto Biológico, São Paulo, Brazil

2 Centro de Pesquisa e Desenvolvimento de Recursos Genéticos Vegetais, Instituto Agronômico, Campinas, Brazil

${ }^{3}$ Departamento de Ciências Exatas e Tecnológicas, Universidade Estadual de Santa Cruz, Ilhéus, Brazil

\section{Edited by:}

Eva-Guadalupe Lizárraga-Paulín, Universidad Nacional Autonoma de Mexico, Mexico

\section{Reviewed by:}

Sergio Enrique Pasteris, Universidad Nacional de Tucumán, Argentina Mehdi Razzaghi-Abyaneh, Pasteur Institute of Iran, Iran

*Correspondence:

Edlayne Gonçalez, Centro de Pesquisa e Desenvolvimento em Sanidade Animal, Instituto Biológico, Av. Conselheiro Rodrigues Alves, São Paulo 1252, Brazil

e-mail: goncalez@biologico.sp.gov.br
Aflatoxin $\mathrm{B}_{1}\left(\mathrm{AFB}_{1}\right)$ is a highly toxic and carcinogenic metabolite produced by Aspergillus species on food and agricultural commodities. Inhibitory effects of essential oils of Ageratum conyzoides (mentrasto) and Origanum vulgare (oregano) on the mycelial growth and aflatoxin $B_{1}$ production by Aspergillus flavus have been studied previously in culture medium. The aim of this study was to evaluate aflatoxin $\mathrm{B}_{1}$ production by Aspergillus flavus in real food systems (corn and soybean) treated with Ageratum conyzoides (mentrasto) and Origanum vulgare (oregano) essential oils. Samples with $60 \mathrm{~g}$ of the grains were treated with different volumes of essential oils, 200, 100, 50, and $10 \mu \mathrm{L}$ for oregano and 50,30,15, and $10 \mu \mathrm{L}$ for mentrasto. Fungal growth was evaluated by disk diffusion method. Aflatoxin $B_{1}$ production was evaluated inoculating suspensions of $A$. flavus containing $1.3 \times 10^{5}$ spores $/ \mathrm{mL}$ in $60 \mathrm{~g}$ of grains (corn and soybeans) after adjusting the water activity at 0.94 . Aflatoxin was quantified by photodensitometry. Fungal growth and aflatoxin production were inhibited by essential oils, but the mentrasto oil was more effective in soybeans than that of oregano. On the other hand, in corn samples, the oregano essential oil was more effective than that of mentrasto. Chemical compositions of the essential oils were also investigated. The GC/MS oils analysis showed that the main component of mentrasto essential oil is precocene I and of the main component of oregano essential oil is 4-terpineol. The results indicate that both essential oils can become an alternative for the control of aflatoxins in corn and soybeans.

Keywords: corn, soybeans, essential oil, mycotoxins, Origanum vulgare, Ageratum conyzoides

\section{INTRODUCTION}

Loss of food commodities due to pest infestations is a major reason of food crisis particularly in tropical countries (Prakash et al., 2013). Grains and cereals are exposed in the field and also during the storage subjected to a wide variety of organisms. Among these organisms, fungi can cause a lot of damage to the grains during planting, harvesting, and storage (Sillker and Elliot, 1980). The economic impact of fungal invasion include the decline of the power of germination, moldering visible discoloration, odor, chemical, and nutritional changes, with consequent loss of quality, mycotoxin production, making them unfit for consumption (Paster and Bullerman, 1988). The grains serve as a suitable substrate for mold growth and mycotoxin production (Bryden, 2012). The presence of molds and mycotoxin in food commodities is a potential health threat to humans and livestock.

Mycotoxins are toxic substances that can enter the human and animal food chain, not only by the direct ingestion of contaminated seeds or processed food, but also by the consumption of meat or other animal products (i.e., milk) from livestock fed with feed and contaminated silages (Zjalic et al., 2006).

Aflatoxins are mycotoxins produced especially by Aspergillus flavus, A. parasiticus, and A. nomius, and they are mutagenic and carcinogenic in animals and humans. Overall, there are a number of approaches that can be taken to minimize mycotoxin contamination in animal feeds and these involve prevention of fungal growth and therefor mycotoxin formation and strategies to reduce or eliminate mycotoxins from contaminated commodities, especially feed additives (Bryden, 2012). The exploitation of natural substances with bioactivity against fungi has been the target of interest in the search for ecologically safe products (Passone et al., 2012).

Of many approaches investigated to manage aflatoxin contamination, chemical control methods using essential oils have shown great promise. Numerous essential oils produced by medicinal plants have been tested for their ability in controlling aflatoxin contamination in culture medium conditions (Omidbeygi et al., 2009; Kumar et al., 2010; Nogueira et al., 2010; Medeiros et al., 2011), but there is scanty information concerning essential oils for protection of grains contaminated with aflatoxins. In recent studies, the literature relates antifungal and antiaflatoxigenic activity by essential oils on peanut, wheat, and chickpea (Passone et al., 2013; Kedia et al., 2014).

Ageratum conyzoides (mentrasto) and Origanum vulgare (oregano) essential oils have been reported as inhibitors of growth and production of aflatoxin $\mathrm{B}_{1}$ by $A$. flavus in culture medium (Montes-Belmont and Carvajal, 1998; Nogueira et al., 2010), but in real food systems (corn and soybean) no reports. In this work corn and soybean grains, experimentally contaminated 
with $A$. flavus, were treated with $A$. conyzoides and $O$. vulgare essential oils to evaluate aflatoxin $B_{1}$ production. The chemical compositions of both essential oils also were investigated.

\section{MATERIALS AND METHODS PLANT MATERIAL}

Aerial parts of $A$. conyzoides were collected in Ibiúna City, São Paulo State, Brazil. A voucher specimen ( $\mathrm{N}^{\circ}$ PMSP 9686b) was deposited in the herbarium of the City Hall of São Paulo City. $O$. vulgare was bought in shops in the city of São Paulo, Brazil.

\section{OIL EXTRACTION AND ANALYSIS}

Fresh leaves of $A$. conyzoides cut into small pieces and dried $O$. vulgare were placed in a distillation Clevenger apparatus for $2 \mathrm{~h}$. The hydrolytes were extracted with hexane and evaporated at room temperature, and the resulting oil was stored in dark glass bottles in a freezer until be used in A. flavus and GC/MS analysis.

GC/MS analyses of the main components of the essential oils were performed on a Shimadzu QP-5000 equipped with an OV-5 $(30 \mathrm{~mm} \times 0.25 \mathrm{~mm} \times 0.25 \mu \mathrm{m}$, Ohio Valley Specialty Chemical, Inc.) capillary column. Operating conditions were undertaken at oven temperature from 60 to $240^{\circ} \mathrm{C}$ at $3^{\circ} \mathrm{C} \mathrm{min}{ }^{-1}$, injector and detector temperatures of 240 and $230^{\circ} \mathrm{C}$, respectively, at $70 \mathrm{eV}$. Helium was used as a carrier gas at a constant flow of $1.7 \mathrm{~mL} \mathrm{~min}^{-1}$, split $1 / 20$. The oil components were identified using retention indices with those of authentic compounds or with literature data (McLafferty and Stauffer, 1989; Adams, 2001).

\section{CULTURE CONDITIONS}

The aflatoxin $\mathrm{B} 1$ producing strain of $A$. flavus was isolated from soil of a crop rice. It was assigned by the Reference Laboratory of Microbiology located at the Instituto de Tecnologia de Alimentos (ITAL), Campinas City, Brazil. The strain was kept lyophilized in freezer until ready to use.

The strain was reconstituted in sterile water and inoculated in potato dextrose agar (Difco Laboratories) for 10 days at $25^{\circ} \mathrm{C}$. After this period, the cultures are washed with a sterile solution of $1 \%$ Tween 80 .

\section{TEST OF ANTIFUNGAL ACTIVITY OF ESSENTIAL OILS Disk diffusion assay}

Filter paper disks ( $6 \mathrm{~mm}$ diameter) containing $5.0 \mu \mathrm{L}$ of essential oils of $A$. conyzoides and $O$. vulgare were applied on the surface of potato dextrose agar (Difco Laboratories) plates previously inoculated with A. flavus. The inoculated plates were incubated at $25^{\circ} \mathrm{C}$ for 5 days. At the end of the period, antifungal activity was evaluated by measuring the zone of inhibition ( $\mathrm{mm}$ ) against the test fungus (Yin and Tsao, 1999).

\section{Test in grains (in vivo)}

The fungal growth was also evaluated in grains, using the same methodology above, but the paper disc was replaced by grains (corn and soybeans).

Commercial fungicide was used as a positive control. All treatments consisted of three replicates and repeated once more. The averages of the experimental results were determined.

\section{EVALUATION OF AFLATOXIN PRODUCTION IN CORN AND SOYBEANS IMPREGNATED WITH ESSENTIAL OILS}

Samples with $60 \mathrm{~g}$ of each grain (corn and soybeans) were irradiated with a dose of $20 \mathrm{kGy}$, at the Instituto de Pesquisas Energéticas Nucleares (São Paulo City), to eliminate the fungal contamination. For evaluation of aflatoxin B1 production in the grains, the samples were placed in erlenmeyer flasks; the water activity was adjusted to 0.94 , and the samples were treated with $200,100,50$, and $10 \mu \mathrm{L}$ of oregano essential oil and 50,30, 15, and $10 \mu \mathrm{L}$ of mentrasto essential oil. Untreated samples were used as control.

Suspensions of $A$. flavus containing $1.3 \times 10^{5}$ spores $/ \mathrm{mL}$ were inoculated in the grains treated and untreated with the essential oils. Four replicates were performed for each treatment, and the experiment was repeated twice.

The cultures were incubated at $25^{\circ} \mathrm{C}$ for 10 days for aflatoxin production, then grain samples were ground. Thereafter, $50 \mathrm{~g}$ of each sample was used for extraction of aflatoxin through the method of Soares and Rodriguez-Amaya (1989). Aflatoxin $B_{1}$ was extracted with chloroform and the solvent evaporated until $1.0 \mathrm{~mL}$ in a volumetric flask. An aliquot $(40 \mu \mathrm{L})$ of each sample was spotted on silica gel-G thin layer plate (Merck, Germany) and then developed with chloroform:acetone 9:1 (v:v) as a solvent system. The concentration of aflatoxin $B_{1}$ was determined by photodensitometry (Shimadzu, CS 9000) comparing the area of the spot samples with aflatoxin $\mathrm{B}_{1}$ standards (Sigma Aldrich, USA). The quantification and detection limits for $\mathrm{AFB}_{1}$ were 0.08 and $0.04 \mathrm{ng}$, respectively.

\section{STATISTICAL ANALYSIS}

The experiments were analyzed by ANOVA and Tukey's multiple range tests with a significance level $P<0.05$. The $\mathrm{IC}_{50}$ was calculated by GraphPad Prim 5.0 software.

\section{RESULTS}

\section{CHEMICAL COMPOSITION}

The essential oils extracted from A. conyzoides and O. vulgare yielded 0.042 and $0.27 \%$, respectively. Chemical analysis by GC/MS of the components of the oils led to identification of 5 and 18 components of the essential oil of $A$. conyzoides and of that of $O$. vulgare, respectively (Tables 1, 2). The major components of $A$. conyzoides oil were precocene I $(96.53 \%)$ and precocene II $(2.40 \%)$ and those of $O$. vulgare essential oil were 4-terpeniol (44.11\%), linalool (15.22\%), and thymol (13.40\%).

\section{FUNGAL GROWTH}

The fungal growth inhibition assessed by the disk diffusion test has been used in the evaluation of plant extracts and essential oils (Reddy et al., 2008; Humeera et al., 2013).

The influence of the essential oils on the inhibitory zone against $A$. flavus were measured at 1.9 and $0.88 \mathrm{~mm}$ (average $n=6$ ) for $A$. conyzoides and $O$. vulgare, respectively. The commercial fungicide (control) was measured at $2.15 \mathrm{~mm}$. The results obtained by the disk diffusion method were 88.37 and $40.93 \%$ of inhibition of fungal growth for the A. conyzoides and $O$. vulgare essential oils respectively, when compared with control. 
Table 1 | Components identified as constituents of essential oil of Ageratum conyzoides (\%).

\begin{tabular}{lcccc}
\hline Constituents & $\boldsymbol{R T}$ (min.) & [\%] & $\boldsymbol{I R}^{*}$ & $\boldsymbol{I R}^{* *}$ \\
\hline n-Tetradecane & 23.540 & $\operatorname{tr}$ & 1400 & 1400 \\
Trans-caryophillene & 24.198 & $\operatorname{tr}$ & 1416 & 1418 \\
a-Humulene & 25.562 & $\operatorname{tr}$ & 1449 & 1454 \\
$\begin{array}{l}\text { Dimetoxy ageratocromene } \\
\text { (Precocene I) }\end{array}$ & 25.749 & 96.53 & 1454 & 1463 \\
$\begin{array}{l}\text { Ageratocromene } \\
\text { (Precocene II) }\end{array}$ & 33.220 & 2.40 & 1659 & 1660 \\
\hline
\end{tabular}

${ }^{*}$ Experiment retention indices; ${ }^{* *}$ literature retention indices (Adams, 2001); RT, retention time; $t r$, traces of substance ( $\operatorname{tr} \leq 0.59)$.

Table 2 | Components identified as constituents of essential oil of Oreganum vulgare (\%).

\begin{tabular}{lcccc}
\hline Constituents & $\boldsymbol{R T}$ (min.) & {$[\%]$} & $\boldsymbol{I R}^{*}$ & $\boldsymbol{I R}^{* *}$ \\
\hline o-Cimene & 7.974 & 0.99 & 1013 & 1022 \\
p-Cimene & 8.194 & 1.08 & 1019 & 1026 \\
Limonene & 8.388 & 0.26 & 1025 & 1031 \\
$\boldsymbol{\gamma}$-Terpinene & 9.421 & 5.02 & 1053 & 1062 \\
Trans-sabinene hidrate & 9.688 & 1.79 & 1061 & - \\
Terpinolene & 10.520 & 0.70 & 1084 & 1088 \\
Linalool & 10.827 & 15.22 & 1093 & 1098 \\
Trans-p-mentenol & 10.892 & 3.31 & 1095 & - \\
Cis-p-mentenol & 11.732 & 1.99 & 1116 & - \\
Borneol & 12.433 & 1.34 & 1133 & - \\
4-terpineol & 13.981 & 44.11 & 1171 & 1177 \\
$\alpha$-Terpineol & 14.493 & 5.96 & 1184 & 1189 \\
Dihydro carveol & 14.733 & 0.36 & 1190 & 1192 \\
2-Isopropyl-5-methyl-anisole & 16.348 & 0.47 & 1228 & 1235 \\
2-Isopropyl-5-methyl-anisole & 16.738 & 1.49 & 1238 & 1244 \\
Geraniol & 17.293 & 1.46 & 1251 & -
\end{tabular}

*Experiment retention indices; ** literature retention indices (Adams, 2001); RT, retention time; $t$, traces of substance ( $t r \leq 0.59$ ).

The test in grains of corn for A. conyzoides inhibited at $79.53 \%$ the fungal growth. But in the other experiments with grains, no halo formation around the grain, but the fungus did not grow on the grain.

\section{AFLATOXIN PRODUCTION}

All concentrations of the two essential oils reduced aflatoxin $B_{1}$ production in corn and soybeans samples when compared with the control (Figures 1, 2), using the same inoculum $\left(1.3 \times 10^{5}\right.$ spores/mL).

The volumes 50,30, and $15 \mu \mathrm{L}$ of $A$. conyzoides essential oil inhibited aflatoxin $\mathrm{B}_{1}$ production in corn at 93.70, 34.15, and $15.45 \%$, respectively $(P<0.01)$. The volumes $50,30,15$, and $10 \mu \mathrm{L}$ of the $A$. conyzoides essential oil showed inhibitory effect on aflatoxin production in soybeans above $75 \%$ when compared with the control and between their treatments $(P<0.001)$ (Figure 1).
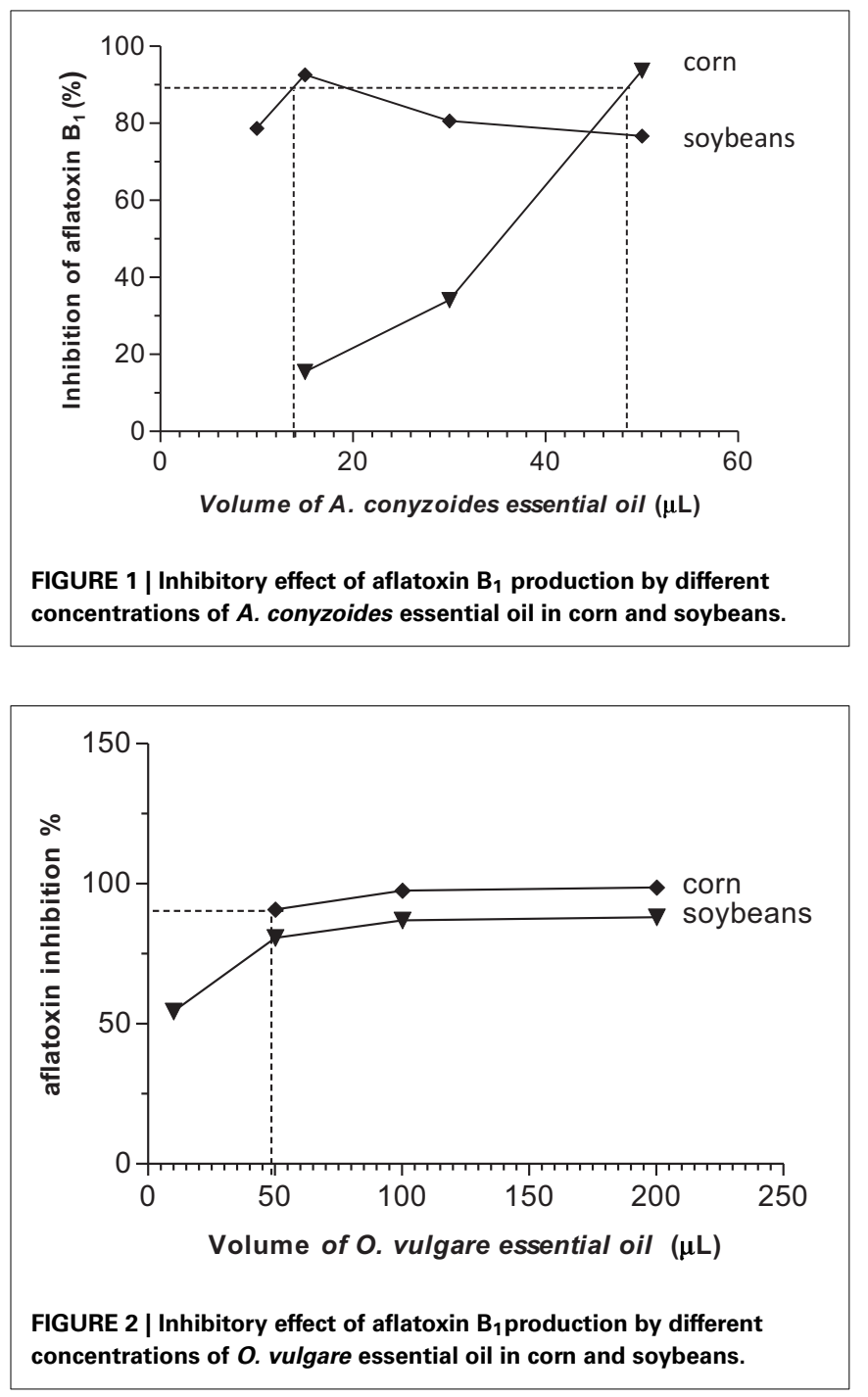

As regards $O$. vulgare essential oil, the volumes of 10, 50, 100 , and $200 \mu \mathrm{L}$ showed inhibitory effect on aflatoxin production in soybeans at $54.4,88.68,86.94$, and $88.16 \%$, respectively (Figure 2). There was a significant inhibition of aflatoxin $B_{1}$ production in soybeans as compared with that of the control $(P<0.01)$. On the order hand, $O$. vulgare essential oil in corn showed an inhibitory effect up to $90 \%$ on mycotoxin/aflatoxin B1 production for all concentrations tested $(P<0.001)$ (Figure 2$)$.

The volumes of the $A$. conyzoides essential oil that inhibited $90 \%$ of aflatoxin production were 14.1 and $48.5 \mu \mathrm{L}$ for soybeans and corn, respectively. To O. vulgare essential oil was $49.8 \mu \mathrm{L}$ for corn, but was not observed for soybeans.

\section{DISCUSSION}

Both essential oils have been described as inhibitors of the fungal growth of $A$. flavus. Montes-Belmont and Carvajal (1998) related inhibition of $A$. flavus growth at concentration up to $1000 \mu \mathrm{g} \mathrm{g}^{-1}$ of $O$. vulgare essential oil. Montes-Belmont and Carvajal (1998) related that inhibition of $A$. flavus growth that occurred at concentration up to $1000 \mu \mathrm{g} \mathrm{g}^{-1}$ 
of O. vulgare essential oil. Nogueira et al. (2010) reported that A. conyzoides essential oil inhibited the fungal growth to $48 \%$ in culture medium.

The results of inhibition of fungal growth obtained allowed continuing our study, thus enabling us to verify the activity of these two essential oils in grains (corn and soybean) in order to envision their potential use as antifungal and/or antiaflatoxigenic.

The two essential oils reduced the production of aflatoxin $\mathrm{B}_{1}$ in corn and soybean samples when compared (Figures 1, 2). O. vulgare essential oil showed an inhibitory effect up to $85 \%$ in corn and soybeans at 200,100 , and $50 \mu \mathrm{L}(P<0.01)$. In the volumes of 200,100 , and $50 \mu \mathrm{L}$ of the $O$. vulgare essential oil showed significant inhibition of the aflatoxin $\mathrm{B}_{1}$ production in corn as compared to control $(p<0.001)$. However, in sample with 200 and $100 \mu \mathrm{L}$ of $O$. vulgare essential oil statistically significant differences were not observed in the aflatoxin production $(p>0.05)$. The $100 \mu \mathrm{L}$ of $O$. vulgare essential oil showed significant inhibition of aflatoxin $\mathrm{B}_{1}$ production in soybeans when compared to the control and among the samples $(P<0.01)$.

The statistic results and volumes of the essential oils that inhibited $90 \%$ of aflatoxin production showed that $A$. conyzoides essential oil was more active than that of $O$. vulgare in soybeans. On the other hand, in corn, the essential oil of $O$. vulgare was more active than that of $A$. conyzoides.

The results are quite interesting and corroborate with data reported by other authors that discussed activity of essential oils in real food systems.

Bluma and Etcheverry (2008) also observed a total inhibition of aflatoxin $\mathrm{B}_{1}$ in corn with $O$. vulgare essential oil at concentrations of 500 and $700 \mu \mathrm{g} \mathrm{g}^{-1}$, using a water activity of 0.955 . Our

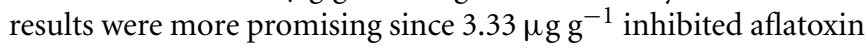
production in corn to $98.68 \%$.

Passone et al. (2013) related that boldo (Peumus boldus Mol.) essential oil showed antifungal activity in peanut extract medium at doses of $1500 \mu \mathrm{L} / \mathrm{L}$, that is, a highly significant effect on Aspergillus section Flavi growth rate (93 and 100\% of inhibition) and aflatoxin B1 (AFB1) accumulation (100\% of inhibition).

Velázquez-Nuñez et al. (2013) compared the antifungal activity efficacy of orange peel essential oil at selected concentrations, applied either by vapor exposure or direct addition on the growth of $A$. flavus. The results encompass both studied methods. A. flavus growth decreased as essential oil concentration increased. Although the effect of orange peel essential oil by direct addition was faster, orange peel essential oil vapors were more effective since lower concentrations of the latter were required to achieve the same antifungal effect.

Differences in the chemical composition and in the biological activity of the essential oils have been discussed by different authors. A. conyzoides essential oil for this study was collected in 2009, and precocene I (96.53\%) was the major constituent. Nogueira et al. (2010) collected A. conyzoides in 2007, at the same venue, but related that precocene II $(46.35 \%)$, precocene I $(42.78 \%)$ were main components. Furthermore, A. conyzoides essential oil collected in 2009 showed other differences in chemical makeup as: it contains fewer chemical constituents, and $n$-tetradecane is a new compound. It has not been previously reported by Nogueira et al. (2010). The differences in chemical composition of essential oils from plants could be explained due to environmental differences that occur from one year to another where they grow. Variations of oil composition of A. conyzoides were related by Castro et al. (2004).

Precocenes I and II have been described as inhibitors of mycotoxins' production. Yaguchi et al. (2009) related that precocenes I and II inhibited 3-acetyldeoxynivalenol production by Fusarium graminearum in a liquid culture with $\mathrm{IC}_{50}$ values of 16.6 and 1.2 ppm, respectively, without inhibiting fungal growth. Precocene II also inhibited deoxynivalenol production by the fungus in a solid culture on rice with an $\mathrm{IC}_{50}$ value of $2.0 \mathrm{ppm}$.

O. vulgare essential oil had as main constituents linalool (45.22\%), 4-terpineol (44.11\%), thymol (13.40\%), $\alpha$-terpineol $(5.96 \%)$, and $\gamma$-terpinene $(5.02 \%)$. The literature reports that the carvacrol and thymol are the main constituents and also responsible for antimicrobial activity of essential oil of oregano (Lambert et al., 2001; Chi et al., 2006), however these authors also observed that the level of each component varied in relation to time of year.

The findings of the present study may draw the attention of food industries to conduct further experiments regarding large scale exploitation of essential oils as preservative of food commodities.

\section{CONCLUSION}

The results showed that the essential oil of $A$. conyzoides inhibits the production of aflatoxin in soybeans more than the essential oil of O. vulgare. On the other hand, in the corn samples, the essential oil of $O$. vulgare was more active, so the choice of treatment should take into account the type of substrate. Nowadays, it has been difficult to control exposure of man and animals to mycotoxins, because these compounds naturally occur in the environment.

Thus, the use of natural compounds like essential oils with lower toxicity than that of synthetic products can be a good alternative for aflatoxin control, and the essential oils of $A$. conyzoides and $O$. vulgare may be a possibility for the protection against the production of aflatoxin B1 in corn and soybeans.

\section{ACKNOWLEDGMENT}

The authors are grateful to Conselho Nacional de Desenvolvimento Científico e Tecnológico (CNPq) and Fundação de Amparo à Pesquisa do Estado de São Paulo (FAPESP) for financial support.

\section{REFERENCES}

Adams, R. P. (2001). Identification of Essential Oil Components by Gas Cromatography/Mass Spectroscopy. Carol Stream, IL: Allured Publ. Corp.

Bluma, R., and Etcheverry, M. (2008). Application of essential oils in maize grain: impact on Aspergillus section Flavi growth parameters and aflatoxin accumulation. J. Food Microbiol. 25, 324-334. doi: 10.1016/j.fm.2007.10.004

Bryden, W. L. (2012). Mycotoxin contamination of the feed supply chain: implications for animal productivity and feed security. Anim. Feed Sci. Technol. 173, 134-158. doi: 10.1016/j.anifeedsci.2011.12.014

Castro, H. G., Oliveira, L. O., Barbosa, L. C. A., Ferreira, F. A., Silva, D. J. H., Mosquim, P. R., et al. (2004). Teor e composição do óleo essencial de cinco acessos de Mentrasto. Quím. Nova 27, 55-57. doi: 10.1590/S010040422004000100011

Chi, S., Zivanovic, S., and Penfield, M. P. (2006). Application of chitosan films enriched with oregano essential oil on bologna- active compounds and sensory attributes. Food Sci. Technol. Int. 12, 111-117. doi: 10.1177/1082013206063845 
Humeera, N., Kamili, A. N., Bandh, S. A., Amin, S. U., Lone, B. A., and Gousia, N. (2013). Antimicrobial and antioxidant activities of alcoholic extracts of Rumex dentatus L. Microb. Pathog. 57, 17-20. doi: 10.1016/j.micpath.2013. 02.001

Kedia, A., Prakash, B., Mishra, P. K., and Dubey, N. K. (2014). Antifungal and antiaflatoxigenic properties of Cuminum cyminum (L.) seed essential oil and its efficacy as a preservative in stored commodities. Int. J. Food Microbiol 168, 1-7. doi: 10.1016/j.ijfoodmicro.2013.10.008

Kumar, A., Shukla, R., Singh, P., and Dubey, N. K. (2010). Chemical composition, antifungal and antiaflatoxigenic activities of Ocimum sanctum L. essential oil and its safety assessment as plant based antimicrobial. Food Chem. Toxicol. 48, 539-543. doi: 10.1016/j.fct.2009.11.028

Lambert, R. J. W., Skandamis, P. N., Coote, P., and Nychas, G. J. (2001). A study of the minimum inhibitory concentration and mode of action of oregano essential oil, thymol and carvacrol. J. Appl. Microbiol. 91, 453-462. doi: 10.1046/j.13652672.2001.01428.x

McLafferty, F. W., and Stauffer, D. (1989). The Wiley/NBS Registry of Mass Spectral Data. New York, NY: John Wiley Sons.

Medeiros, R. T. S., Gonçalez, E., Felicio, R. C., and Felicio, J. D. (2011). Evaluation of antifungal activity of Pittosporum undulatum essential oil against Aspergillus flavus and aflatoxin production. Ciênc. Agrotec. 35, 71-76. doi: 10.1590/S141370542011000100008

Montes-Belmont, R., and Carvajal, M. (1998). Control of Aspergillus flavus in maize with plant essential oils and their components. J. Food Prot. 61, 616-619.

Nogueira, J. H. C., Gonçalez, E., Galleti, S. R., Facanali, R., Marques, M. O. M., and Felicio, J. D. (2010). Ageratum conyzoides essential oil as aflatoxin suppressor of Aspergillus flavus. Int. J. Food Microbiol. 137, 55-60. doi: 10.1016/j.ijfoodmicro.2009.10.017

Omidbeygi, M., Barzegar, M., Hamidi, Z., and Naghdibadi, H. (2009). Antifungal activity of thyme, summer savory and clove essential oils against Aspergillus flavus in liquid medium and tomato paste. Food Control 18, 1518-1523. doi: 10.1016/j.foodcont.2006.12.003

Passone, A. M., Girardi, N. S., Ferrand, C. A., and Etcheverry, M. (2012). Invitro evaluation of five essential oils as botanical fungitoxicants for the protection of store peanuts form Aspergillus flavus and A. parasiticus contamination. Int. Biodeter. Biodegr. 70, 82-88. doi: 10.1016/j.ibiod.2011. 11.017

Passone, M. A., Girardi, N. S., and Etcheverry, M. (2013). Antifungal and antiaflatoxigenic activity by vapor contact of three essential oils, and effects of environmental factors on their efficacy. Food Sci. Technol. 53, 434-444. doi: 10.1016/j.lwt.2013.03.012

Paster, N., and Bullerman, L. B. (1988). Mould spoilage and mycotoxins formation in grains as controlled by physical means. Int. J. Food Microbiol. 7, 257-265. doi: $10.1016 / 0168-1605(88) 90044-X$
Prakash, B., Singh, P., Yadav, S., Singh, S. C., and Dubey, N. K. (2013). Safety profile assessment and efficacy of chemically characterized Cinnamomum glaucescens essential oil against storage fungi, insect, aflatoxin secretion and as antioxidant. Food Chem. Toxicol. 53, 160-167. doi: 10.1016/j.fct.2012.11.044

Reddy, B. S., Reddy, B. P., Raghavulu, S. V., Ramakrishna, S., Venkateswarlu, Y., and Diwan, P. V. (2008). Evaluation of antioxidant and antimicrobial properties of Soymida febrifuga leaf extracts. Phytother. Res. 22, 943-947. doi: 10.1002/ptr.2433

Sillker, J. H., and Elliot, R. P. (1980). Ecologia microbiana de los alimentos. Acribia $1,74-76$.

Soares, L. M. V., and Rodriguez-Amaya, D. B. (1989). Survey of aflatoxin A, zearalenona, and sterigmatocystin in some brazilian foods by using multi-toxin then-layer chromatographic method. J. Assoc. Off. Anal. Chem. 72, 22-26.

Velázquez-Nuñez, M. J., Avila-Sosa, R., Palou, E., and López-Malo, A. (2013). Antifungal activity of orange (Citrus sinensis var. Valencia) peel essential oil applied by direct addition or vapor contact. Food Control 31, 1-4. doi: 10.1016/j.foodcont.2012.09.029

Yaguchi, A., Yoshinari, T., Tsuyuki, R., Takahashi, H., Nakajima, T., Sugita-Konishi, Y., et al. (2009). Isolation and identification of precocenes and piperitone from essential oils as specific inhibitors of trichothecene production by Fusarium graminearum. J. Agric. Food. Chem. 57, 846-851. doi: 10.1021/jf802813h

Yin, M. C., and Tsao, S. M. (1999). Inhibitory effect of seven Allium plants upon three Aspergillus species. Int. J. Food. Microbiol. 49, 49-56. doi: 10.1016/S01681605(99)00061-6

Zjalic, S., Reverberi, M., Ricelli, A., Granito, V. M., Fanelli, C., and Fabbri, A. A. (2006). Trametes versicolor: a possible tool for aflatoxin control. Int. J. Food Microbiol. 107, 243-249. doi: 10.1016/j.ijfoodmicro.2005.10.003

Conflict of Interest Statement: The authors declare that the research was conducted in the absence of any commercial or financial relationships that could be construed as a potential conflict of interest.

Received: 19 March 2014; accepted: 16 May 2014; published online: 04 June 2014 Citation: Esper RH, Gonçalez E, Marques MOM, Felicio RC and Felicio JD (2014) Potential of essential oils for protection of grains contaminated by aflatoxin produced by Aspergillus flavus. Front. Microbiol. 5:269. doi: 10.3389/fmicb.2014.00269 This article was submitted to Food Microbiology, a section of the journal Frontiers in Microbiology.

Copyright (C) 2014 Esper, Gonçalez, Marques, Felicio and Felicio. This is an openaccess article distributed under the terms of the Creative Commons Attribution License (CC BY). The use, distribution or reproduction in other forums is permitted, provided the original author(s) or licensor are credited and that the original publication in this journal is cited, in accordance with accepted academic practice. No use, distribution or reproduction is permitted which does not comply with these terms. 